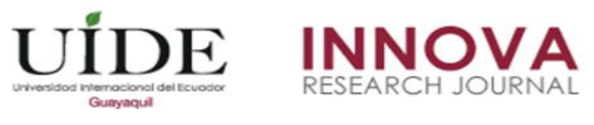

INNOVA Research Journal, ISSN 2477-9024

(Diciembre, 2018). Vol. 3, No.12 pp. 135-147

DOI: https://doi.org/10.33890/innova.v3.n12.2018.708

URL: http://revistas.uide.edu.ec/index.php/innova/index

Correo: innova@uide.edu.ec

\title{
Inclusión financiera de la mujer del mercado informal: análisis de los productos ofertados por parte de las entidades financieras de la ciudad de Loja
}

\section{Financial inclusion of women in the informal market: analysis of the products offered by financial entities in the city of Loja}

Lorena Del Cisne Tacuri Peña

Universidad Internacional del Ecuador, Ecuador

Autora para correspondencia: lorenatacurimed@gmail.com

Fecha de recepción: 08 de junio de 2018 - Fecha de aceptación: 01 de diciembre de 2018

Resumen: Inclusión Financiera dos palabras de uso creciente a nivel mundial, que hoy en día cada vez se abre espacio en nuestro país, misma que busca involucrar a los diversos sectores sociales y vulnerables como es el caso de la mujer como tal, y que de manera cotidiana genera recursos económicos para cubrir las necesidades primarias de su hogar. Es imprescindible destacar el aumento continuo del mercado informal en nuestra ciudad, en donde cuyos montos de apalancamiento financiero se encuentran por debajo de los montos mínimos de otorgamiento de la diversidad de productos, los actores financieros como son las entidades financieras y por ende se visualiza una latente fragilidad económica y que debe ser considerado como segmento prioritario de atención de las entidades públicas y privadas respectivamente. Por tanto la mujer, al ser considerada como un ente generador de ingresos a través del desempeño de sus actividades laborales en el mercado informal, es prioritario y vital su inclusión financiera y el conocimiento de la existencia del portafolio de productos financieros en las diferentes entidades bancarias y cooperativas de ahorro y crédito, permitiendo así el desarrollo de actividades productivas a pequeña escala.

Palabras clave: inclusión financiera; oferta; sector vulnerable; entidades financieras

\begin{abstract}
Financial Inclusion: two words of increasing use worldwide, which nowadays is opening up space in our country, which seeks to involve the different social and vulnerable sectors, as is the case of women as such, and on a daily basis generates economic resources to cover the primary needs of your home.It is essential to highlight the continuous increase of the informal market in our city, where the amounts of financial leverage are below the minimum amounts of granting the diversity of products, financial actors such as financial institutions and therefore visualize a latent economic fragility and that should be considered as a priority segment of attention of public and private entities respectively. Therefore, women, being considered as a generating entity of income through the performance of their labor activities in the informal market, is a priority and vital financial inclusion and knowledge of the existence of the portfolio of financial products in different banking entities and savings and credit cooperatives, thus allowing the development of productive activities on a small scale.
\end{abstract}

Key words: financial inclusion; supply; vulnerable sector; financial entities 


\section{Introducción}

El presente estudio tiene como propósito generar un análisis en el impacto y caracterización de la inclusión financiera de la mujer del mercado informal, y por ende resaltar su bienestar y realización como ente social.

Al tratarse de un proyecto correspondiente al Área Administrativa, y al no generar externalidades negativas en su ejecución no incide en un impacto ambiental, considerando que como todo proyecto de esta índole estará vinculado al respeto de la naturaleza.

Si bien es cierto nuestro país padece en gran medida de aportes y nuevas oportunidades de empleo, con una investigación satisfactoria, y su ejecución se propende consolidar que la mujer es un pilar fundamental en la generación de recursos económicos. Con ello el presente proyecto será bien visto y sin ninguna duda un aporte por parte de la entidad de educación superior hacia las diferentes entidades públicas, y financieras de la ciudad de Loja.

Estos últimos años, algunas instituciones financieras, han enfocado sus colocaciones de crédito directamente al sector micro empresarial, fundamentalmente en los sectores vulnerables manteniendo correspondencia con los objetivos tres y ocho del Buen Vivir y determinantes del comportamiento su dinámica y así poder identificar el impacto de la política pública, privada hacia este sector y formular recomendaciones para su mejoramiento. (Plan del Buen Vivir, 2013)

Actualmente en nuestra sociedad se observa que existen diversas comunidades que están desarrollándose y superándose mediante la implementación de nuevos negocios, pero se encuentran con grandes dificultades por la falta de recursos económicos, y el problema se agrava aún más, cuando no pueden acceder a mecanismos de financiamiento, debido a que las instituciones financieras no les prestan la facilidad de obtener créditos, puesto que como son personas con escasos recursos económicos, o forman parte de grupos vulnerables les es difícil cubrir las elevadas tasas de interés que les imponen dichas instituciones.

\section{Problema}

La ciudad castellana del Sur de la Patria, enfrenta la crisis económica que invade a todo el país, lo que conlleva a que los diferentes sectores vulnerables, la crisis incida más en su precaria economía.

El sector de las micro finanzas en la localidad juegan un papel muy importante en la economía local, conjuntamente con sus servicios de operación, y que sean altos, de similar forma se evidencia que las tasas de interés para los diferentes productos financieros son regulados por la Super Intendencia de Economía Popular y Solidaria.

Por tanto es fundamental resaltar que las instituciones micro financieras, se han creado para contribuir a un desarrollo social, a través del financiamiento de diversidad de portafolio de productos que van en beneficio de sus clientes, con tasas de interés y costos operativosadministrativos bajos. 
Es así que la participación activa del sistema financiero en la colocación de estos fondos provoca cambios sociales a nivel del cliente, su familia y su entorno que le rodea, incidiendo en su bienestar social y económico.

La inclusión financiera está enfocada en contribuir a un desarrollo económico y social según la Constitución de la república del Ecuador de septiembre del 2008 a través de la participación activa de la mujer que desarrolla su actividad económica en el mercado informal, mediante el conocimiento y acceso de productos financieros, logrando la inclusión financiera en las diferentes entidades a nivel local.

\section{Revisión de literatura}

\section{Economía popular y solidaria y su sector financiero.}

\section{Definición.}

La Constitución del Ecuador indica en su artículo 283 que "el sistema económico es social y solidario" (Constitución, 2008). Asimismo especifica en su artículo 276 "El régimen de desarrollo tendrá los siguientes objetivos:

- Mejorar la calidad y esperanza de vida, y aumentar las capacidades y potencialidades de la población en el marco de los principios y derechos que establece la Constitución.

- Construir un sistema económico, justo, democrático, productivo, solidario y sostenible basado en la distribución igualitaria de los beneficios del desarrollo, de los medios de producción y en la generación de trabajo digno y estable.” (Constitución, 2008)

\section{La Economía Solidaria en la Economía Mixta}

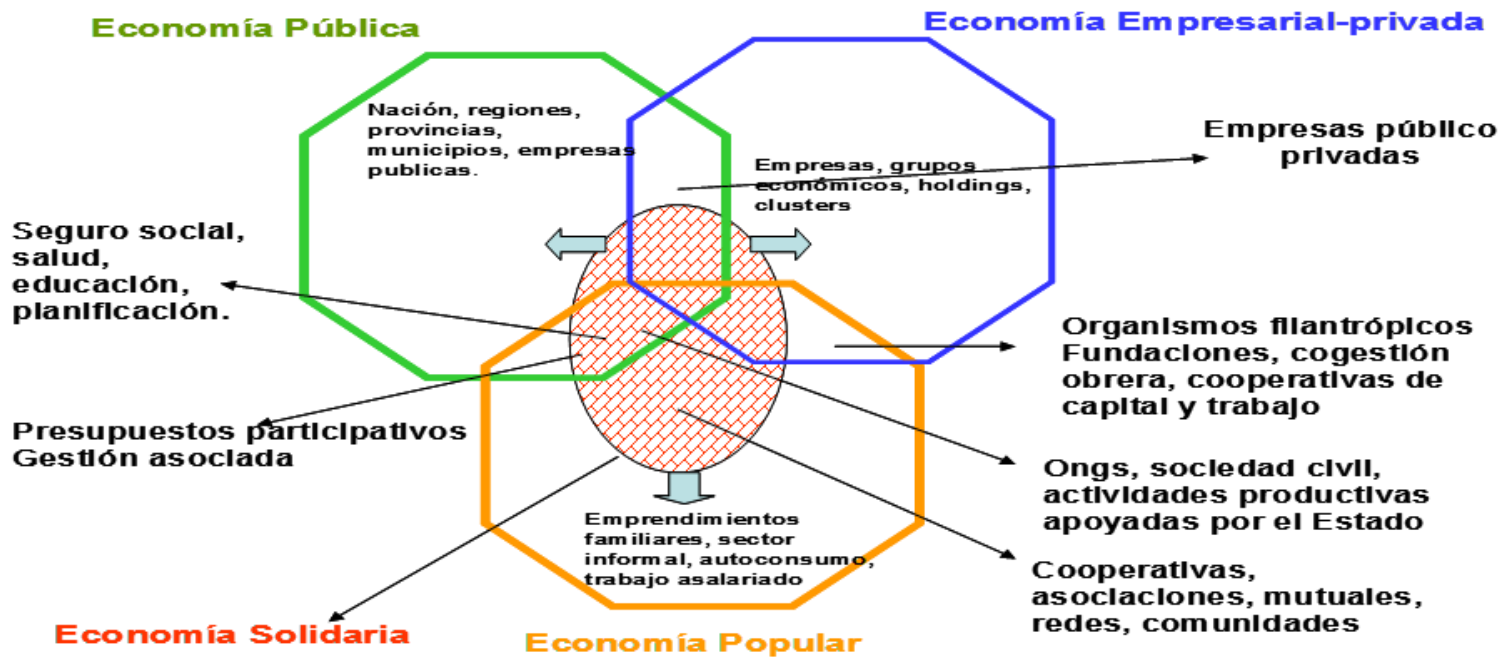

Ilustración 1: Sistema Económico Social y Financiero

Fuente 1: Corporación Nacional de Finanzas Populares y Solidarias.

\section{Actores de las finanzas populares}


Según la Constitución de la República del Ecuador en su Art. 311 el sector financiero popular y solidario se compondrá de: "Cooperativas de ahorro y crédito, entidades asociativas o solidarias, cajas y bancos comunales, cajas de ahorro" (Constitución, 2008), reconociendo que todas estas formas sociales son de distinto tipo y tamaño y generalmente se han creado muchas de ellas en base a prácticas más equitativas y, son claves en el desarrollo social.

\section{Bancos}

Ejercen el comercio de banca las personas naturales o jurídicas que, con habitualidad y ánimo de lucro, reciben del público, en forma de depósito irregular o en otras análogas, fondos que aplican por cuenta propia a operaciones activas de crédito y a otras inversiones, con arreglo a las leyes y a los usos mercantiles, prestando además por regla general a su clientela servicios de giro, transferencia, custodia, mediación y otras en relación con los anteriores, propios de la comisión mercantil. (Martínez, 2009, pág. 21)

\section{Sector público}

Diseñar y ejecutar políticas económicas que permitan alcanzar la sostenibilidad, crecimiento y equidad de la economía para impulsar el desarrollo económico y social del país.

\section{Banco Central del Ecuador}

El banco central del ecuador es el banco central de ecuador. Desde su nacimiento, y hasta 2000, fue el banco nacional emisor de la moneda ecuatoriana conocida como sucre. Tras el proceso de adopción del dólar estadounidense como divisa de cambio (dolarización), sus funciones disminuyeron dramáticamente, aunque se mantiene como el ente regulador de las políticas monetarias del país. (Marulanda, 2007)

\section{Banco del Estado}

Banco de desarrollo es el banco público del ecuador encargado de financiar los servicios públicos, proyectos de inversión e infraestructuras, a través de préstamos a los diversos gobiernos seccionales. El banco ha decidido fortalecer el sistema de crédito público. En ese sentido, el banco del estado ha trabajado directamente con gobiernos subnacionales y comunidades, a diferencia de los bancos comerciales, ejecutando obras públicas que satisfacen sus necesidades básicas. (Junta Bancaría, 2002)

\section{BanEcuador}

Articulado a la institucionalidad y a los objetivos nacionales; con un enfoque inclusivo, créditos adaptados a las condiciones de los sectores productivos $\mathrm{y}$, con horarios adecuados a las actividades de los productores, comerciantes y campesinos. (Ecuador, 2015)

\section{Corporación Financiera}


Corporación financiera es una institución financiera pública, cuya misión consiste en impulsar el desarrollo de los sectores productivos y estratégicos del ecuador, a través de múltiples servicios financieros y no financieros alineados a las políticas públicas.

La acción institucional está enmarcada dentro de los lineamientos de los programas del gobierno nacional dirigidos a la estabilización y dinamización económica convirtiéndose en un agente decisivo para la consecución de las reformas emprendidas. (CFN)

\section{Sector Privado}

Es importante considerar como está estructurado el sector financiero a nivel privado, en nuestro país:

\section{Bancos privados}

Ejercen el comercio de banca las personas naturales o jurídicas que, con habitualidad y ánimo de lucro, reciben del público, en forma de depósito irregular o en otras análogas, fondos que aplican por cuenta propia a operaciones activas de crédito y a otras inversiones, con arreglo a las leyes y a los usos mercantiles, prestando además por regla general a su clientela servicios de giro, transferencia, custodia, mediación y otras en relación con los anteriores, propios de la comisión mercantil. (Martínez, 2009, pág. 21)

\section{Sociedades Financieras}

Las sociedades financieras de objeto múltiple reguladas serán aquellas que mantengan vínculos patrimoniales con instituciones de crédito. (Diputados, 2016, pág. 55)

\section{Mutualistas de ahorro y crédito para la vivienda}

Las asociaciones mutualistas de ahorro y crédito para la vivienda, así como las instituciones de Servicios financieros, entendiéndose por éstas a los almacenes generales de depósito, compañías de arrendamiento mercantil, compañías emisoras o administradoras de tarjetas de crédito, casas de cambio, corporaciones de garantía y retrogarantía, corporaciones de desarrollo de mercado secundario de hipotecas, que deberán tener como objeto social exclusivo la realización de esas actividades, quedarán sometidas a la aplicación de normas de solvencia y prudencia financiera y al control que realizará la superintendencia dentro del marco legal que regula a dichas instituciones, en base a las normas que expida para el efecto. (SISTEMA, 2014, pág. 1)

\section{Compañías de seguros y reaseguros}

El seguro de depósitos tiene por objeto proteger los depósitos efectuados en las cooperativas de ahorro y crédito, entidades asociativas o solidarias, cajas y bancos comunales y en las cajas de ahorro, reguladas por esta ley. (Jurídico, 2016, pág. 51)

\section{Servicios complementarios}


El sector de servicios complementarios al sector financiero aglutina a las empresas que ofrecen productos y servicios a entidades orientadas a atender los segmentos de población Considerados dentro del ámbito de la inclusión financiera. (AFI, pág. 2)

\section{Servicios auxiliares}

Las instituciones de servicios auxiliares del sistema financiero, tales como: transporte de especies monetarias y de valores, servicios de cobranza, cajeros automáticos, servicios contables y de computación, fomento a las exportaciones e inmobiliarias propietarias de bienes destinados exclusivamente a uso de oficinas de una sociedad controladora o institución financiera; y, otras que fuesen calificadas por la superintendencia de bancos, sin perjuicio del control que corresponde a la superintendencia de compañías, serán vigiladas por la superintendencia de bancos y ésta dictará normas de carácter general aplicables a este tipo de instituciones. (SISTEMA, 2014, pág. 2)

\section{Sector popular y solidario}

El sector financiero popular y solidario se compondrá de cooperativas de ahorro y crédito, entidades asociativas o solidarias, cajas y bancos comunales, cajas de ahorro. Las iniciativas de servicios del sector financiero popular y solidario, y del micro, pequeñas y medianas unidades productivas, recibirán un tratamiento diferenciado y preferencial del estado, en la medida en que impulsen el desarrollo de la economía popular y solidaria. (Jurídico, 2016, pág. 19)

\section{Cooperativas de Ahorro y Crédito}

Según la Ley de Cooperativas, señala que: "Son cooperativas las sociedades de derecho privado, formadas por personas naturales o jurídicas que, sin perseguir finalidades de lucro, tienen por objeto planificar y realizar actividades o trabajos de beneficio social o colectivo, a través de una empresa manejada en común y formada con la aportación económica, intelectual y moral de sus miembros" (Ley de Cooperativas, 2001)

\section{Fuentes De Financiamiento}

\section{Fuentes y formas principales de financiación a corto plazo.}

El crédito comercial: Un tipo común de crédito comercial es el préstamo para capital de trabajo, diseñado para apoyar operaciones comerciales en curso. (Madura, 2012, pág. 482)

Préstamos de bancos comerciales: El principal uso o aplicación de los fondos del banco es para préstamos. El importe del préstamo y el vencimiento pueden adaptarse a las necesidades del prestatario. (Madura, 2012, pág. 482)

Línea de crédito: el objetivo de este contrato es que la empresa tenga lista una fuente de financiamiento para el momento contingente que lo requiera. El plazo de contratación es por un año y el monto del crédito se entrega en cualquier momento siempre dentro del plazo contratado a solicitud de la empresa. (Arturo Morales, 2014, pág. 88) 
Sectores Vulnerables

En el Art.35 de la Constitución de la República del Ecuador considera a los sectores vulnerables como "personas adultas mayores, niñas, niños y adolescentes, mujeres embarazadas, personas con discapacidad” (Constitución, 2008)

- Servicios financieros diversificados dirigidos al micro emprendimientos.

- Sostenibilidad: desempeño económico y desempeño comercial, a través de indicadores financieros como, Calidad de cartera, eficiencia y productividad, la gestión financiera, y la rentabilidad; hablar sobre la cartera de riesgo, micro emprendimiento.

\section{Objetivo}

Realizar un estudio y análisis de la demanda de los servicios ofertados por parte de las entidades financieras de la ciudad de Loja

\section{Metodología}

En el presente estudio se realizó a través de una investigación de tipo Descriptiva, bajo la aplicación de la técnica de la entrevista a los analistas responsables del portafolio de productos, así mismo se realiza una investigación de tipo documental en base a las fuentes bibliográficas indagadas, revisión de registros de entidades financieras, gráficos de revistas, periódicos físicos y on-line de información directa al objeto de estudio.

Para la ejecución de la investigación se contará con un docente y un alumno perteneciente a la Facultad de Ciencias Administrativas y Económicas.

\section{Técnicas}

Entrevista: estará dirigida al analista responsable directo de los productos financieros, y de manera específica al sector bancario, y para las cooperativas de ahorro y crédito de la ciudad de Loja. Así mismo se aplicará una entrevista directa al gerente de dichas entidades para conocer su percepción frente a la inclusión financiera, y así sustentar la información en lo referente a la aceptabilidad de su portafolio de productos por parte de la mujer del mercado informal de la ciudad de Loja.

Se aplicará el instrumento a todas las entidades financieras registradas tanto en la Superintendencia de Bancos y la Superintendencia de Economía Popular y Solidaria.

\section{Resultados}

Análisis de la inclusión financiera de la mujer a nivel mundial, datos extraídos de la base de datos de Global Findex database. (Banco Mundial, 2018) 


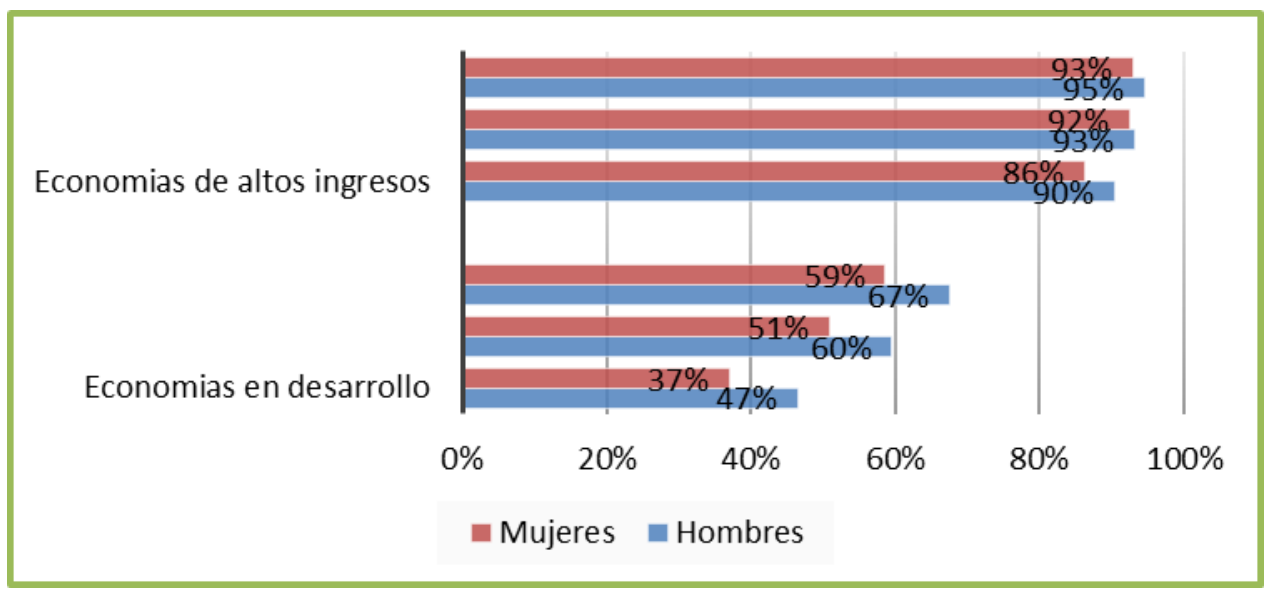

Gráfica 1: Inclusión financiera a nivel mundial.

Fuente: Global Findex-Base de datos de Inclusión Financiera en el mundo

De acuerdo a los resultados de la gráfica a nivel mundial el 69\% de los adultos que corresponde a 3800 millones de personas, actualmente poseen una cuenta en una entidad financiera, según la base de datos de Global Findex, entre el año 2014 hasta el 2017, aperturaron cuentas 515 millones de adultos, considerando que algunos países han registrado progresos más lentos (Banco Mundial, 2018).

Análisis de la inclusión financiera de la mujer a nivel nacional, datos extraídos de la base de datos del Banco Central del Ecuador.

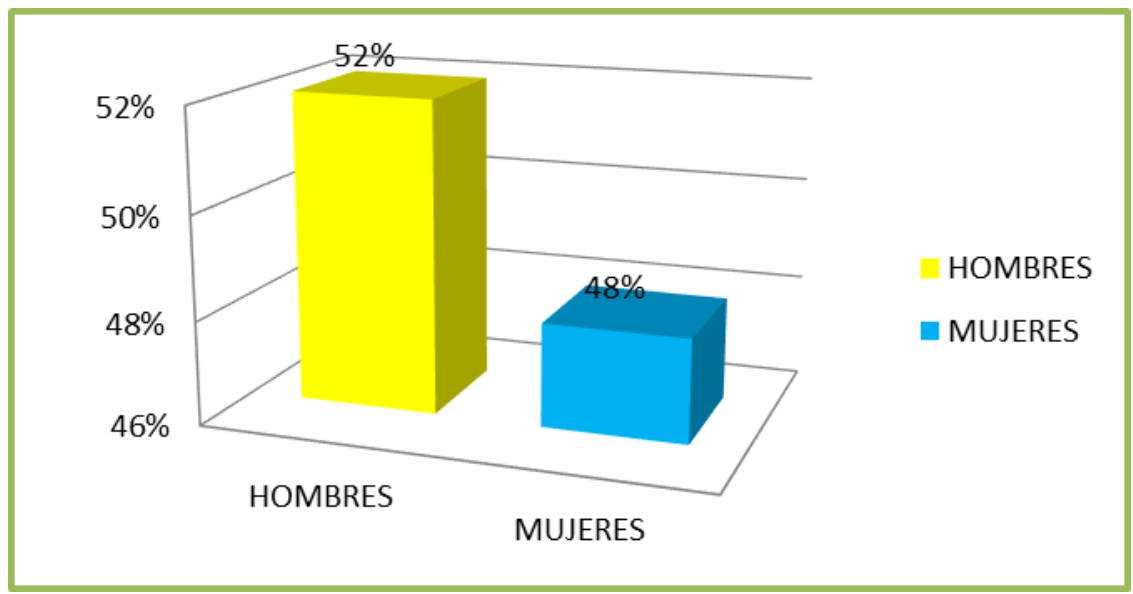

Gráfica 2: Inclusión financiera de la mujer a nivel nacional Fuente: Banco Central del Ecuador-Base de datos de Inclusión Financiera

De los 17 millones de ecuatorianos, el $44 \%$ tienen acceso a diversos servicios que ofertan las instituciones financieras, según los datos del Banco Central del Ecuador, con relación a la gráfica y con la proporción descrita, señalamos que $52 \%$ corresponde al segmento de hombres y el $48 \%$ restante corresponde a la segmentación de mujeres, manteniendo correspondencia estos resultados con la información de Global Findex a nivel mundial. 
Análisis de la inclusión financiera de la mujer en la ciudad de Loja, datos extraídos de la base de datos del Banco Central del Ecuador.

\section{Inclusiòn Financiera en la Ciudad de Loja}

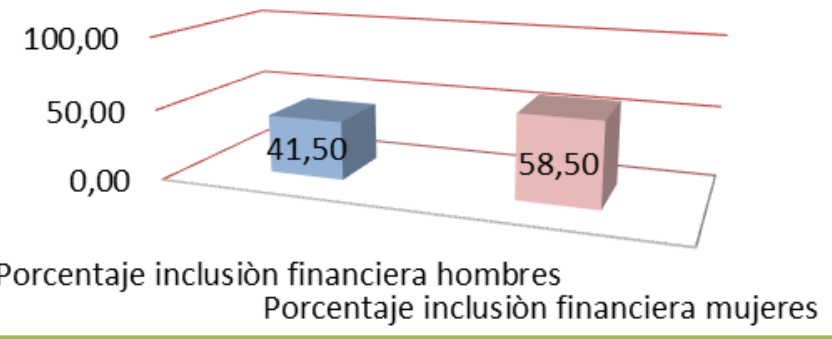

Gráfica 3: Inclusión financiera de la mujer en la ciudad de Loja Fuente: Banco Central del Ecuador-Base de datos de Inclusión Financiera

De una población adulta proyectada de 169.618 habitantes en la ciudad de Loja para el año 2017, se considera según datos del Banco Central que el 58,58\% están incluidos financieramente, y de acuerdo a esta proporcionalidad el $41,50 \%$ pertenece a los hombres para el período 2017.

Análisis de la inclusión financiera de la mujer en la ciudad de Loja con el producto activos, datos extraídos de la base de datos del Banco Central del Ecuador.

\section{Inclusión Financiera: Crédito}

- Hombres Mujeres

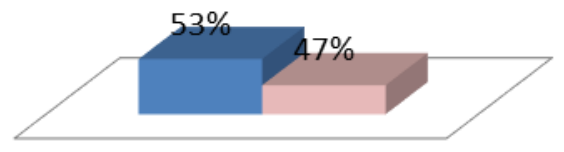

Gráfica 4: Inclusión financiera producto crédito

Fuente: Banco Central del Ecuador-Base de datos de Inclusión Financiera

Al analizar el indicador de inclusión financiera de clientes por sexo en el producto activos que corresponde a Crédito, que es ofertado por todas las entidades financieras de la ciudad de Loja, denotamos que el $53 \%$ le corresponde a los hombres y el $47 \%$ es para la mujer.

El crédito comercial, efectivamente, es un préstamo de una empresa a otra, pero está vinculado a una compra. (Aranday, 2017, pág. 87) 
A los que no cuentan con poder adquisitivo suficiente para "comprar" sus satisfacciones que pueden ser desde productos básicos hasta muebles, tecnológicos, ropa, por lo que para no "perder a estos clientes" se les consigue mediante líneas bancarias (tarjetas bancarias) hasta productos financieros como el factoraje financiero.

Es fundamental en los resultados, señalar las entidades financieras que existen en la ciudad de Loja y que en el estudio las clasificamos en Bancos y Cooperativas de Ahorro y Crédito indicando así mismo los productos que ofertan con mayor permanencia para la ciudadanía Lojana, en la tabla siguiente:

Tabla 1: Bancos y Cooperativas en la ciudad de Loja

\begin{tabular}{lll}
\hline Bancos & 12 & Crédito Automotriz. \\
& & Crédito de consumo. \\
& & Crédito hipotecario. \\
& Crédito para empleados. \\
Cooperativas De Ahorro Y Crédito & 25 & Microcrédito \\
& & Crédito de consumo \\
& Crédito emergente \\
\hline
\end{tabular}

\section{Fuente: Súper Intendencia de Bancos y Seguros y Economía Popular y Solidaria} Elaborada por la autora

\section{Discusión}

Con respecto a nivel mundial la inclusión financiera está aumentando de manera acelerada, pero estos logros han sido dispares de un país a otro, y de acuerdo a la gráfica se puede concluir que los hombres siguen teniendo más probabilidades que las mujeres.

A nivel nacional el porcentual de inclusión financiera tanto de hombres como de mujeres mantiene correspondencia con los resultados a nivel mundial, datos que son emitidos por el Global Findex.

En la ciudad de Loja y de acuerdo a los datos emitidos por el Banco Central del Ecuador hasta el año 2017, la proporción mayor en porcentaje le corresponde a la mujer y en menor porcentual al hombre, por lo que se puede concluir que la inclusión de la mujer es significativa en esta ciudad y para el respectivo período

Con referencia al acceso y otorgamiento de crédito, los resultados es evidente que aún en nuestro medio continua prevaleciendo más apertura a los productos financieros para el hombre, en tanto que para la mujer se mantiene restricción a estos servicios únicamente por ser mujer, aún más cuando forma parte del estrato de menos recursos económicos.

Finalmente se indago sobre las instituciones financieras en la ciudad de Loja, y que comprenden Bancos y Cooperativas de Ahorro y Crédito, obteniendo como resultados que existen 12 Bancos con un portafolio de productos que ofertan a la ciudadanía Lojana como 
crédito de consumo, crédito vehicular, crédito de vivienda, credi confianza, crédito verde, credi rol, crédito emergente, entre otros, con respecto a las Cooperativas de Ahorro y Crédito existen 12 , con productos como el crédito al socio, microcrédito, crédito convenio institucional, crédito salud emergente, crédito educativo, entre otros, donde es muy notable que ambos van a la captación de clientes pero en las Cooperativas de Ahorro y crédito se enfocan en el sector social.

\section{Conclusiones}

La inclusión financiera llegó para quedarse, y si sus actores protagónicos cumplen correctamente con sus respectivas tareas, tiene todas las posibilidades de crecer y posicionarse como unos de los referentes estratégicos relevantes de las economías de nuestro país, aún más en estos tiempos digitales, así mismo es considerada como un elemento de desarrollo social, y promueve el acceso de la población más vulnerable a los diferentes productos que ofrece el Sistema Financiero Nacional.

Finalmente se debe considerar el mercado objetivo de las iniciativas de inclusión financiera es la población de menores recursos económicos, ubicada en la base de la pirámide social, es así como se debe buscar incorporar a la mujer del mercado informal a los beneficios de crecimiento económico, dándole acceso a todos los servicios financieros desde los básicos como pagos y remesas así como los más sofisticados que se encuentran los créditos y seguros, y es así como la política pública de la inclusión financiera debe tener como fin último acrecentar la capilaridad de los sistemas financieros, bajar costos, y eliminar los obstáculos para que la mujer del mercado informal de la ciudad de Loja y el país acceda de manera totalitaria a estos productos.

\section{Bibliografía}

Biess. (2012). Obtenido De Https://Www.Biess.Fin.Ec/Nuestra-Institucion/Historia

Buen Vivir. (S/D De S/M De 2013). Recuperado El 17 De Mayo De 2016, De Buen Vivir: Http://Www.Buenvivir.Gob.Ec/Objetivos-Nacionales-Para-El-Buen-Vivir

Afi. (S.F.). Servicios Complementarios Al Sector Financiero. España: Onim

Aranday, F. R. (2017). Finanzas Corporativas: Una Propuesto Metodológica. Insitituto Mexicano De Contadores Públicos.

Arturo Morales, J. A. (2014). Administración Financiera. Df México: Grupo Editorial Patria.

Ávila, Y. L. (2004). Introducción A La Economía. Plaza Y Valdéz S.A.

Banco Mudial. (19 De Abril De 2018). Global Findex. Recuperado El 12 De Mayo De 2018, De Global Findex: Http://Www.Bancomundial.Org

Banco Mundial. (19 De Abril De 2018). Global Findex. Recuperado El 12 De Mayo De 2018, De Global Findex: Http:/Www.Bancomundial.Org/Es/News/Press- 
Release/2018/04/19/Financial-Inclusion-On-The-Rise-But-Gaps-Remain-Global-FindexDatabase-Shows

Banco Popular Dominicano. (15 De Junio De 2015). Impulsapopular. Recuperado El 13 De Marzo De 2018, De Impulsapopular: Https://Www.Impulsapopular.Com/Gerencia/Que-Es-ElPotencial-Humano-Y-Como-Medirlo/

Bravo, M. (2015). Contabilidad General. Quito: Ediciones Macro.

Briceño, P. L. (2016). Apuntes De Finanzas Operativas. Lima: Editorial De La Universidad Peruana De Ciencias Aplicadas. CFN. (S.F.). Corporación Financiera Nacional. Obtenido De Https://Www.Cfn.Fin.Ec/Corporacion-Financiera-Nacional/

Constitución, 2. (2008). Constitución Dejemos El Pasado Atrás. Quito: Publicación Oficial De La Asamblea Constituyente.

Coopmego. (17 De Septiembre De 2013). Megoline. Obtenido De Https://Coopmego.Com/Megoline

Diputados, C. D. (2016). Ley General De Organizaciones Y Actividades Auxiliares Del Crédito. Dm México. Obtenido De Https://Www.Mdconsult.Internacional.Edu.Ec:2095/Lib/Bibliovirtualuidesp/Reader.Acti on?Docid=4794628\&Query=Sociedades+Financieras

Dumrauf, G. (2013). Finanzas Corporativas. Un Enfoque Latinoamericano. Buenos Aires: Alfaomega.

Ecuador, B. (2015). Ban Obtenido De Https://Www.Banecuador.Fin.Ec/Institucion/Historia/

Fao. (S/D De S/M De 2012). Org. Recuperado El 18 De Junio De 2016, De Http://Www.Fao.Org/Docrep/017/I3027s/I3027s03.Pdf

Fernández, J. (2016). La Empresa Pendiente. Bogotá: Alfaomega Colombiana S.A.

Hernández, M. Á. (2015). Estrategias Y Prácticas En La Concesion Y Uso De Créditos. Df: Trillas.

Humano, I. D. (S.F.). Obtenido De Http://Www.Fomentoacademico.Gob.Ec/FilosofiaOrganizacional/

Junta Bancaría. (2002). Resolución 457. 47. Quito: Junta Bancaría.

Jurídico, D. (2016). Ley Orgánica De Economía Popular Y Solidaria. Quito: Cep Corporación.

Ley De Cooperativas. (2001). Registro Oicial Nro. 400. Quito: Ley De Cooperativas. 
Madura, J. (2012). Mercados E Instituciones Financieras. Df: Cengage Learning.

Martinez, R. (2009). Productos Financieros Básicos Y Su Cálculo. Alicante: Club Universitario.

Marulanda, B. (2007). Micro finanzas Y Pobreza. Bogotá: Merpd- Departamento Nacional De Planeación.

Münch, L. (2014). Fundamentos De Administración (10a Ed.). México: Trillas, S.A.

Pazmiño, I. (2008). Tiempo De Investigar. Quito: Editeka.

Pineda, R. \&., \& Carvallo, P. (2010). El Futuro De La Micro finanzas En América Latina. Santiago De Chile: Cepal.

Rfd. (17 De Mayo De 2016). Www.Rfd.Org.Ec. Obtenido De Www.Rfd.Org.Ec: Http://Rfr.Org.Ec/Index.Php/Blog/395-2016-08-17-17-16-13.Html

Sistema, L. O. (2014). Ley Organica De Instituciones Del Sistema. Quito.

Wikipedia. (S.F.). Obtenido De Https://Es.Wikipedia.Org/Wiki/Banco_Central_Del_Ecuador 